\title{
Engagement leading to empowerment-digital innovation strategies for patient care continuity
}

\author{
Mohan Tanniru ${ }^{1,2}$ \\ ${ }^{1}$ College of Public Health, University of Arizona, Tucson, AZ, USA; ${ }^{2}$ Henry Ford Health System, Detroit, MI, USA \\ Correspondence to: Mohan Tanniru. 24412 South Boxwood Drive, Sun Lakes, AZ, USA. Email: tanniru@oakland.edu.
}

\begin{abstract}
Background: Over the last two decades, digital transformations, i.e., business transformations using advanced technologies, have extended business reach into the customer decision-making process, enabling firms to support two major types of customer services: empowerment services prior to purchase and engagement services during and post-purchase. Service organizations such as health care, by virtue of their intense engagement with patients during in-patient care, have a unique opportunity to extend this engagement with these patients' post-discharge to best tailor digital transformation strategies to address continuity of care, and potentially help empower patients to manage their health condition.
\end{abstract}

Methods: Deductive reasoning was used to assess the focus of digital transformations over the last two decades on value creation through services. These include awareness and decision support services prior to the purchase of a product/service (pooled together as "empowerment" services), and purchase and "use" services that occur during and post-purchase (pooled together as "engagement" services). Four healthcare case studies were studied in-depth to inductively identify factors that are shown to have an influence on continuity of patient care outside the hospital.

Results: The factors shown to have influence include the degree of support patients have from their network of family, friends, and other resources (referred to as the ecosystem) and the complexity of their own health condition. Recognizing these factors can help a hospital tailor its digital transformation strategy by allowing multiple actors to support a hospital's engagement with patients' post-discharge. These actors, both clinical and non-clinical care providers, may help extend a patient's self-efficacy to manage their own health condition (i.e., empower the healthcare consumer).

Conclusions: Understanding factors influencing the patient ecosystem and engaging support groups in patient engagement post-discharge is consistent with prior research that argued for connecting social and clinical diagnosis, if continuity of patient care is the goal. Such a recognition can help tailor digital transformation strategies to address select care needs of the patient population. Future research may use digital transformation goals in patient engagement and empowerment to a healthcare organization's readiness as patient demographics and expectations change.

Keywords: Continuity of patient care; engagement and empowerment services; digital transformation; health IT

Received: 21 December 2018; Accepted: 29 August 2019; Published: 09 October 2019.

doi: 10.21037/jhmhp.2019.09.01

View this article at: http://dx.doi.org/10.21037/jhmhp.2019.09.01

\section{Introduction}

Digitization has advanced the reach of businesses into customer decision making and has transformed the way firms have started to address evolving customer expectations with competitive value propositions. The evolving technology landscape will continue to influence a customers' desire to search, select, purchase, and continually assess their decisions post-purchase, and this has increased the speed with which businesses have to design and deliver services (1). The need for businesses to react faster in such a digital age has been widely discussed (2), and firms are asked to become service centric in their approach to co-create 
value propositions and fulfil them using several internal and external resources $(3,4)$.

Healthcare organizations (from here on are referred as hospitals, even though the discussion applies to any care delivering clinic) have started to engage in digital transformations to take advantage of advanced digitization opportunities in order to improve care quality and patient satisfaction. Some of these transformations are focused on improving hospital operations, such as the use of electronic medical records to share patient data by clinical and administrative personnel. Others include the use of radio-frequency identification (RFID) tags and/or real-time locator sensors (RTLS) to track patient flows in emergency departments to reduce delays and improve patient and nurse/physician communication (5), allocate operating rooms for surgeries optimally using data analytics (6), and reduce patient falls, hospital acquired infections, etc. in patient rooms (7). Besides digital transformations, several process-focused transformations are being explored to improve patient engagement using inter-disciplinary rounding (8) and support patient-centric care by re-thinking the way hospital space is allocated for patient comfort (9).

Given the importance of extending patient care post-discharge, prior research (10) has identified several discharge services hospitals can use for digital transformations. For example, discharge services such as outpatient follow-up, improved communication, medication reconciliation, and collaboration with care providers can all be supported using a mix of technologies like mobile text alerts, tele-health technologies, and patient portals (11). Similarly, wearables are being used to track patient conditions remotely and allow home or remote care to become a viable option for sustained patient engagement in care continuity (12). However, many of the transformations are hospital centric (e.g., driven by the needs of the hospital to reduce readmission costs) and focused on care delivered to certain patient types post-discharge (e.g., critically ill), rather than being tailored to address the care-related needs of all healthcare consumers discharged.

A patient-centric approach to digital transformation strategy formulation is a unique challenge to hospitals. Unlike other businesses, healthcare services are not purchased like many products/services. Where a patient gets treated is often determined by a physician and not a patient, unless it is a well-defined commodity type service (e.g., getting corrective lenses, seeking dental care, or pursuing some well-established elective surgeries). Also, postdischarge engagement of a hospital with a patient is not expected to lead to a repeat purchase (i.e., readmission of a patient for the same health condition is often a reflection of poor care quality). Also, the context that plays a role in developing value propositions for healthcare in each phase of the patient care cycle are different: pre-admission that supports wellness or prevention, care inside a hospital, and care post-discharge. Therefore, both co-creation of value propositions $(3,13)$ and fulfilling these propositions using digital transformation strategies inside and outside the hospital need a broader understanding of these contexts (14). The objective of this paper is to begin to develop a framework to understand the patient context, with a focus on one end of the patient care cycle, post-discharge care, in order to guide the digital transformation strategies of hospitals.

The paper is organized as follows. The next section categorizes the service encounters used to fulfill customer value propositions by using a deductive analysis of digital transformations over the last two decades. Section Three uses the patient journey post-discharge in four case studies to inductively derive some factors that have an influence on continuity of care post-discharge. Section Four develops a two-by-two grid that connects the patient health condition with the level of support they receive from their ecosystem to help tailor a hospital's digital transformation strategies to support continuity of care. The last section provides some concluding comments and discusses a research agenda for the future.

\section{Methods}

Advanced digitization in the 21 st century brought customers into the extended business value chain and expanded the need for digital (or IT-enabled) services to create competitive value for customers. These "digital services" are designed to allow customers to use mobile and wireless access to gather information and evaluate products and services before they make purchase decisions. Once a decision is made to purchase, customers expect the purchase to occur in varying modes for convenience and comfort and seek replacement and/or maintenance as needed post-purchase. To understand the evolution of digital transformations of digital or traditional companies, we tracked the value propositions of several companies in the US (see Table 1) that offered digital (IT-enabled) services to their customers. These include both product and service companies, including healthcare firms.

To simplify the categorization of customer services 
Table 1 US digital companies analysed

\begin{tabular}{|c|c|c|}
\hline \multicolumn{3}{|c|}{$\begin{array}{l}\text { IPO SCOOP Rating Performance of Tech Stocks } \\
\text { https://www.iposcoop.com/ }\end{array}$} \\
\hline \multicolumn{3}{|c|}{$\begin{array}{l}\text { Chicago top } 100 \text { tech companies } \\
\text { https://www.builtinchicago.org/2017/10/24/chicago-top-100-tech-companies-2017 }\end{array}$} \\
\hline \multicolumn{3}{|l|}{$\begin{array}{l}\text { CB Insights - } 2018 \text { Digital Health Trends } \\
\text { https://www.cbinsights.com/research/ }\end{array}$} \\
\hline \multicolumn{3}{|c|}{$\begin{array}{l}\text { Top } 100 \text { Companies in Digital Health-Dr. Betalan Mesko } \\
\text { https://leanpub.com/medicalfuturist100 }\end{array}$} \\
\hline \multirow{3}{*}{$\begin{array}{c}\text { Engagement } \\
\text { Action (during use) } \\
\text { Action (during purchase) } \\
\text { Empowerment } \\
\text { Design/choice } \\
\text { intelligence }\end{array}$} & $\begin{array}{l}\text { Support purchase and } \\
\text { post purchase use }\end{array}$ & $\begin{array}{l}\text { Align operations and supply } \\
\text { chain for sale and retention }\end{array}$ \\
\hline & $\begin{array}{l}\text { Support customer decision } \\
\text { making }\end{array}$ & $\begin{array}{l}\text { Align operations and supply chain for } \\
\text { competitive offer }\end{array}$ \\
\hline & $\begin{array}{l}\text { Customer Interfacing } \\
\text { larketing, outbound logistics, sales, } \\
\text { service) + support activities }\end{array}$ & $\begin{array}{l}\text { Business operations } \\
\text { Operations, inbound logistics + support } \\
\text { activities }\end{array}$ \\
\hline
\end{tabular}

Figure 1 Services developed to support customer decision-making and action.

designed to provide value to customers, we mapped these services to each phase of the customer decision-making process: intelligence, design, or choice (15) or customer action: purchase or use post-purchase. This led to our categorizing the services that supported the intelligence, design, and choice phases as "empowerment services," as they are designed to help customers seek information and make decisions on what to purchase. The awareness services support customers' acquisition of knowledge about a product/service, and decision support services help them evaluate the features of a product/service against their decision criteria before they make a final decision. The engagement services include customers' actions to purchase the product/service and its "use" post-purchase.

The empowerment and engagement services are in turn supported by the business value chain (16). We classified the value activities as customer interfacing activities (primary and support activities, such as marketing, sales, distribution, and service after sale used to interact and engage customers) and business operations (all other activities, including the supply chain, to support customer interfacing activities). The digital transformation challenge for businesses today is to transform business operations with speed and agility (Figure 1). Speed is critical for faster alignment of business operations with customer decision making, as businesses empower customers to evaluate value propositions (or competitive offers) and engage the customers during purchase and post-purchase "use". Agility in business operations is essential if the customer wants to explore product/service configuration options prior to purchase or seek changes post-purchase as expectations change. In other words, businesses must adapt the (technical) design and (business) delivery of (digital) services to empower and engage customers through their evolving customer journeys.

The introduction of the internet/web, social media sites, and on-line product or service reviews, etc, have transformed the way customers become "aware" of product/ service offerings and the way firms provide services to broaden customer awareness of business offerings. With 
many new digital intermediaries assisting customers in comparing competing value propositions, firms must rethink the way they help support customer decision making. Decision support services for customers have become increasingly complex as firms come to understand the criteria customers use to make decisions as well as the evolving nature of these criteria with changing market dynamics and customer ecosystems.

In healthcare, both awareness and decision support services are influenced by the way care choices are made by patients, with physicians influencing many of these choices. While commodity type health services (eye care, dental care, or routine and simple surgeries) are following similar trends as those seen in other types of retail services, sustained care quality and clinical reputation still plays an important role in influencing customer decision making on where care delivery is sought, unless insurance options narrow the set of choices. This makes hospital engagement with patients ("services" delivered in the hospital and postdischarge) influential in customer empowerment (i.e., their future decision making to a certain degree).

The purchase process itself can be complex if the level of investment made by the customer is significant and the product sought is not a commodity type. Similarly, products and services with longer "use" cycles post-purchase benefit from opportunities to engage with customers to improve customer satisfaction and brand loyalty. Digital transformations in support of such use cycles include ways to remotely monitor such use and improve the customer experience. With longer "use" cycles, there are more opportunities to gather information about customer journeys after purchase and help support the customer experience to influence their future decisions. Service firms with a shorter use cycle (e.g., restaurants, travel, entertainment services, etc.) have their purchase and use cycles comingled, thus making their "engagement services" influential in customer empowerment in the future. Surveys following engagement, addressing potential problems quickly, and seeking positive reviews can all influence customer empowerment.

Health care organizations have a unique challenge as well as an opportunity. They have two sets of co-mingled engagement and use cycles: a shorter engagement/use cycle while a patient is in the hospital, and a potentially longer engagement/use cycle if the health condition needs sustained care treatment and/or monitoring. Many digital transformations today support patient engagement while a patient is inside a hospital to improve patient satisfaction and, in some cases, physician satisfaction for future referrals of their patients to the hospital. With reimbursements in the US focusing on patient readmissions and bundled payments (where hospitals are paid for care over a longer time), and with hospitals around the world looking to reduce costs and patient congestion in the hospitals, engagement with patients outside the hospital is becoming a high priority. This leads to an engagement challenge for hospitals: How can a hospital best develop and/or tailor its digital transformation strategies to support patient engagement, while recognizing that patients' abilities to follow-through on treatment recommendations vary significantly and often depend on the degree of support they have outside of the hospital?

The next section will look at four case studies of hospital engagement with patient care post-discharge in order to understand factors influencing care outside a hospital.

The study is based on four previously published case studies, referenced in the article, and acknowledged at the start of the paper. No approval by an institutional review board was needed.

\section{Results}

\section{Four case studies}

For simplification, we view health care customers of 500 bed teaching hospital located in the Detroit metropolitan area as an example to define four different patient states: "bealthy state, health maintenance state, health-monitoring state (e.g., chronic conditions), and patient state". A healthcare customer can move from a healthy state to a health maintenance state if certain health conditions, such as high blood pressure, high cholesterol, obesity, etc. are identified as sources for future complications. The health maintenance state, if not supported effectively, can lead to more serious health conditions that may require a continual health monitoring state (e.g., diabetes type 1 or 2, a heart condition, or other chronic conditions). When a healthcare consumer comes to a hospital, he or she is in a "patient" state seeking care-related inpatient services. A customer can move from a patient state to any other state once discharged. Independent of how a customer's journey led him/her to a patient state, the focus here is on what happens to a patient once they are discharged from the hospital.

\section{Case study 1: RSVP system}

RSVP stands for the Remote Specialist Visiting Physicians 


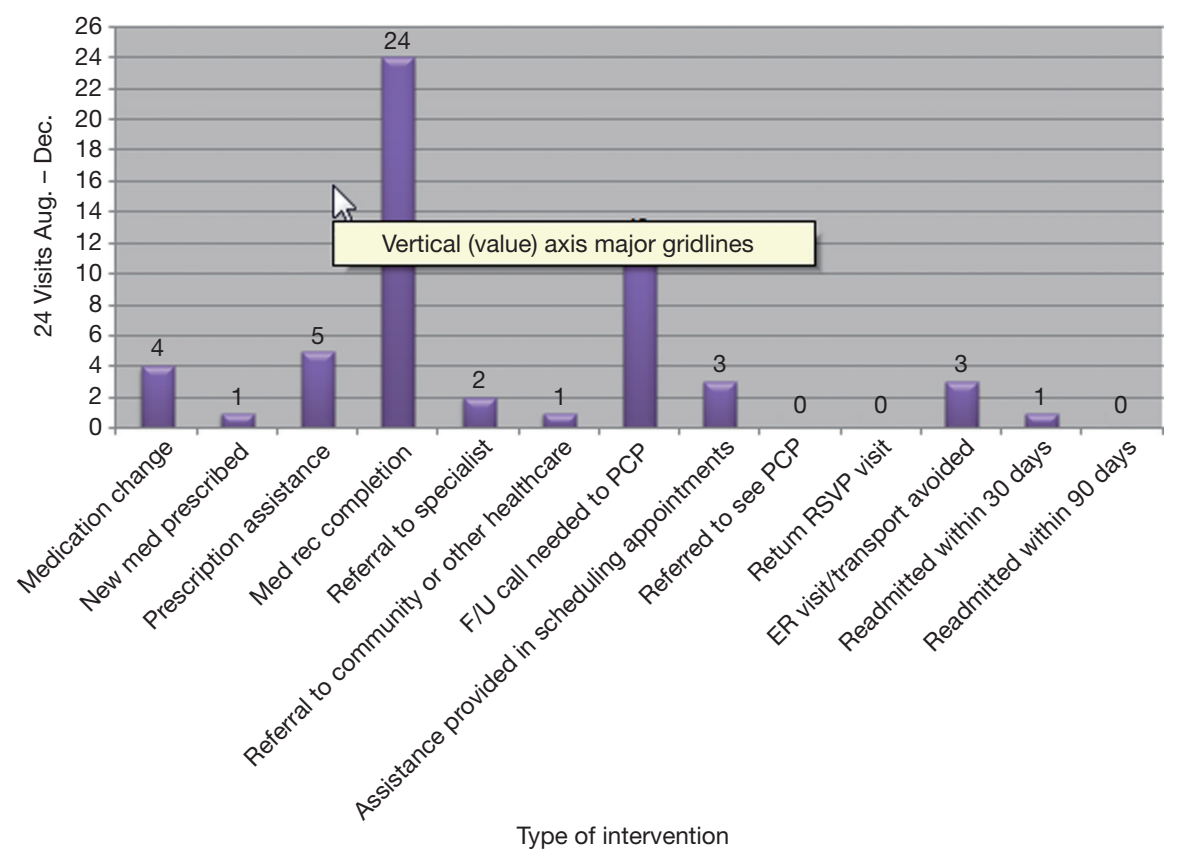

Figure 2 Visit intervention data.

program (17). Once certain patients who are considered high risk are discharged, external care coordinators are recruited from the local fire department-emergency medical technicians (EMTs). They visit patients as a followup and engage in a two-way consultation with emergency room (ER) physicians using video conferencing technology. In addition, the hospital partnered with Vivify Health, which provides a kit to help patients monitor their vital signs and consult with a hospitalist at the hospital as needed. The program's goal is to stop the escalation of illnesses and reduce unnecessary hospital readmissions. The success of the pilot effort in reducing readmissions led the hospital to extend it to other patients in other regions. The engagement here includes patients in a supportive ecosystem (patients living at home).

An early evaluation of the system in 2015 showed benefits when interacting with high-risk patients. This pilot program provided patients with additional support as they transitioned to home recovery, and it was offered as a free service at the point of discharge. The home visits were tailored to a patient's individual health care needs and to ensure continuity of care into and throughout the home recovery process, ultimately improving patient outcomes. Figure 2 illustrates how the intervention was used to provide clarification on medication, scheduling appointments, answering questions, etc. The goal of these interventions was to reduce readmission, and evidence from preliminary data (number of patients involved is too small to make statistically valid predictions) has shown a marked reduction in patient readmissions. Despite resource constraints, such as ER physician availability for consultation and a limited number of kits to distribute to patients, the program is being expanded to another Michigan region. This shows the organization's confidence in the care continuity approach.

Factors that are influential in addressing continuity of care include: external care providers like EMTs in the region, care providers inside the hospital such as ER physicians and hospitalists, as well as technology to track patient conditions and support remote communication. The patient is a resident at home and is viewed as capable of engaging in the needed consultation.

\section{Case study 2: physician/nurse intervention}

Hospital led interventions to reduce readmissions have been discussed in the literature (18). In this case, the hospital used a team of a physician and an advanced nurse practitioner (NP) to coordinate the care of cardiac patients who were discharged to a nursing home (19). The program started in March 2011, and the frequent personal visits of either or both team members to the nursing home helped educate the nursing home staff on what symptoms to look 

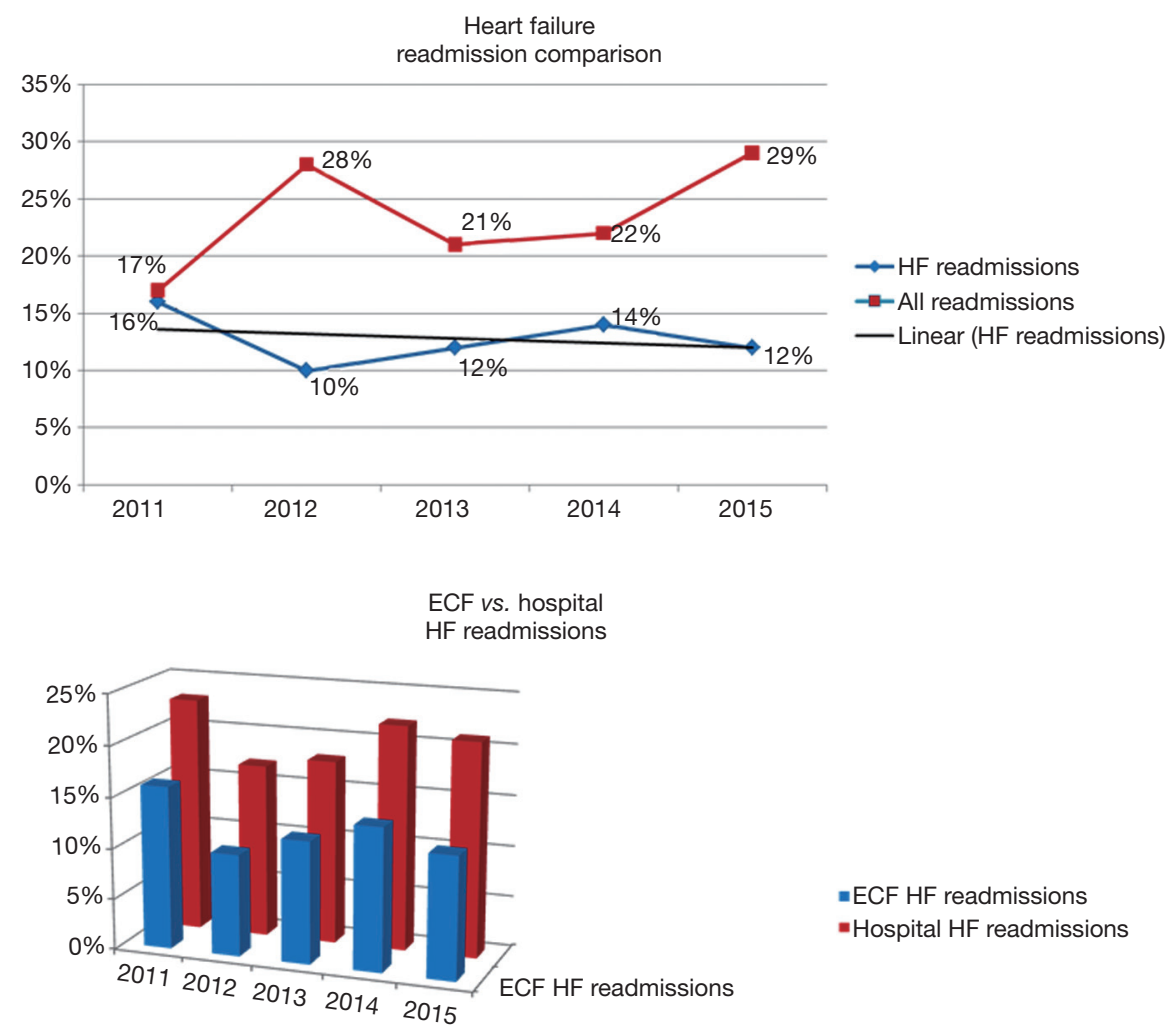

-ECF HF readmissions

-Hospital HF readmissions

Figure 3 Trends in patient readmission.

for when a patient is in an agitated state. The primary goals of the intervention were to improve transitions of care by decreasing medication errors, improving the quality of care post-discharge, reducing readmissions to the hospital and ECF (elderly care facility, such as a nursing home), as well as improving knowledge deficits in cardiovascular disease. The cardiology department, ECF, and other sources such as CMS (Centres for Medicare \& Medicaid Services, US Government) pilot funded the program. The cardiology team supporting the intervention included the cardiologist, cardiology nurse practitioner, administrative director, director of nursing, and medical director of ECF. The intervention program used the following steps:

(I) All patients with a diagnosis of cardiovascular disease are identified. The LPN (licensed practical nurse) assigned to cardiology services generates the patient list (10-15/week), follows up on cardiology orders and ensures their completion, and communicates with the cardiologist or NP on urgent issues as they arise. The SNF is in hospital;

(II) The cardiology NP evaluates new patients using extensive medical chart review/documentation, orders diagnostic tests, makes medication adjustments, and collaborates closely with the cardiologist;

(III) Cardiology services are available during the week for urgent care issues and are managed by the same cardiac team at the hospital whenever possible to improve transition of care.

The skilled nursing staff can use the cardiology team for consultation over the phone or in person to address the situation at the nursing home itself, rather than sending the patient to the ED (emergency department). Based on experiences over 4 years, the following areas were identified as needed for success: follow-up plan postdischarge; documentation of previous cardiovascular procedures; correct medication reconciliation; management of protocols regarding medical devices such as pacemaker/ internal cardiac defibrillator (ICD) registry, venous thromboembolism prophylaxis (VTD) (prevention), atrial fibrillation, coronary stent, peripheral arterial disease/ ischemic foot, etc.; and initiation of a cardiovascular preventive medicine program. The intervention led to a reduction in readmissions as shown in Figure 3 below for 
those patients with heart failure. Based on these results, the program is being expanded to other nursing homes in Michigan, with the expectation that tele-health monitoring devices and mobile apps can help support the increased scale of the patient/care staff engagement.

Factors that are influential in addressing continuity of care include: external care providers like nursing staff and hospital care providers such as surgeons and advanced nurse practitioners working under their guidance, with the potential for technology providing access to needed education and consultation. The patient is in a nursing home and is constantly under the care of the nursing home staff. For all practical purposes, the patient may not be capable of engaging in the needed consultation. Family members may participate in some of the social support.

\section{Case study 3: social worker engagement}

Recognizing the impact of socioeconomic status on diabetes, the Mobile Health Program in Seattle, managed by the Global to Local (20) organization, recruited several health care consumers after they visited a hospital. The aim was to ensure that these patients maintained their health condition or potentially improve it, but not suffer deterioration. The community that was selected experienced significantly higher rates of poverty and premature death, had many immigrants and refugees, and faced multiple barriers to accessing health care and navigating carerelated practices and systems. The study provided iPhones and allowed patients to participate in customized healthy cooking classes once a month, taught by a nutritionist. In addition, the patients interacted with their case manager [community health worker (CHW)] via reports sent from an iPhone-compatible application that tracked blood sugar levels, nutrition, and exercise.

The pilot study included participants who had an average age of 56, were uninsured at the start of the program, had limited English-speaking capability, had average Hba1c of $8.5 \%$ or greater, were new to technology, and were local to the community being supported. The participants sent a weekly report consisting of five or more blood sugar readings to a Global to Local case manager who then tracked their progress while providing a remote support system for disease management. Thirty-six of 49 patients completed the program, with the following improvements in the clinical outcomes.

* $36 \%$ of the participants reduced hemoglobin A1c (HbA1c) by an average of $1.26 \%$ when comparing baseline to completion $(\mathrm{P}=0.04)$;

* A reduction in A1c can help reduce the risk of eye, kidney, and nerve diseases by approximately $40 \%$ and diabetes-related death by $21 \%$.

* The patients' nutrition in-take improved, with $25 \%$ increasing whole grain intake, reducing fat intake, and increasing protein intake;

* The patients' exercise regime improved, with $50 \%$ increasing their frequency of exercise, and $20 \%$ going from not exercising to exercising 30 minutes a day, 2-3 times a week.

The patients' behaviors also changed based on their feedback. Seventy percent enjoyed the use of smart phones, and a similar percentage felt that they were easy to use. Eighty percent felt in control of their health as the program enabled them to track their progress, provided reminders to take tests, and made them aware of the need to monitor their health. All patients felt that the feedback/support was needed to enable them to sustain the progress they made. Ninety-five percent said they would continue to use the smart phone apps, with $50 \%$ preferring text messages, $25 \%$ preferring calls, and $25 \%$ preferring both calls and texts. Sixty-five percent read the case managing texts immediately after receiving a text from their case manager, and $85 \%$ responded to the weekly case managing texts.

Factors that are influential in addressing continuity of care include: social and community care providers who act as intermediaries between hospitals and the patient population, and technology to provide education and access to information needed to manage health conditions. Hospitals may provide some remote access to care-related information, and patients have limited a support system to manage their care condition other than social care workers.

\section{Case study 4: self-bealth management}

Several seniors at a community centre for the elderly in Michigan were interviewed to assess their health maintenance needs (21). While many identified ways to get care-related alerts contextually (when they are watching television or interacting with others socially), they expressed the desire to use technology to allow their family members to participate in their care and related activities to reduce stress (e.g., that is caused by a car not working or heating system failures, loneliness, etc.). A pilot technology implementation was used to gain additional feedback from the seniors. The pilot tool used TV as the main source of information and the smartphone as a 'remote' 
to manage TV content, with a Google Chrome dongle and programming APIs as conduits for bringing the above two together.

The focus was on health, entertainment, and activity needs, as shown in the Figure 4 below. The user could select an option. If the TV option was chosen, a reminder on prescription was provided as a ticker at the top of the screen to improve medication adherence. Other technologies/APIs used included: Google Cast API, MongoDB, Picasa Web Albums Data API, Domino's Pizza API, NodeJS, JavaScript, HTML 5, Java, Android, and Android Speech Recognizer. Feedback from seniors was positive, and further extensions to this approach are being investigated.

The factors that are influential in addressing continuity of care here include external care providers providing

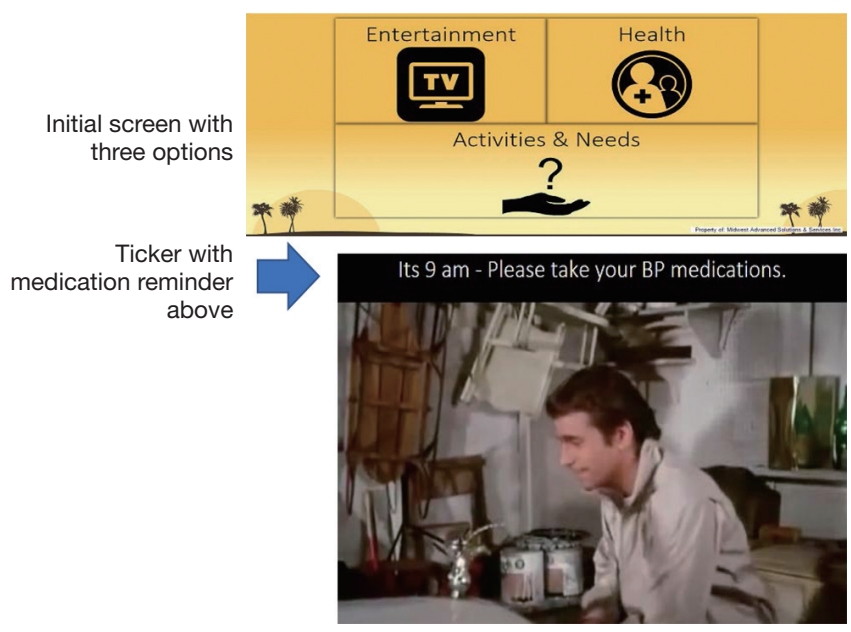

Figure 4 Patient interaction with television. needed support, along with other service providers who can provide complementary services besides supporting healthcare-related consultation. Technology plays a major role in connecting care and non-care related providers with patients. Patients are operating from home and are viewed as capable of engaging in the needed consultation.

These four cases summarize four different types of engagement (care management grid) as shown in Figure 5. Quadrant 2 engages health care consumers at nursing homes to monitor their health using a mix of healthcare providers and nursing facility personnel, while Quadrant 1 engages healthcare consumers needing healthcare maintenance using social workers and community members. The RSVP system was designed to support health monitoring of healthcare consumers using a mix of physicians and other community care providers (Quadrant 4), while seniors living at home need to maintain their health using reminders and stress reducing activities (Quadrant 3).

The next section will discuss the use of the care management grid (shown in Figure 5) to help tailor digital transformation strategies to support patient engagement post-discharge.

\section{Discussion}

Several digital transformation strategies are used today to support patient engagement post-discharge. However, for these strategies to be effective, they need to support the engagement of several actors in the patient network, depending on where a patient resides in the grid. While healthcare research discusses the importance of connecting hospitals with external care providers who provide post-

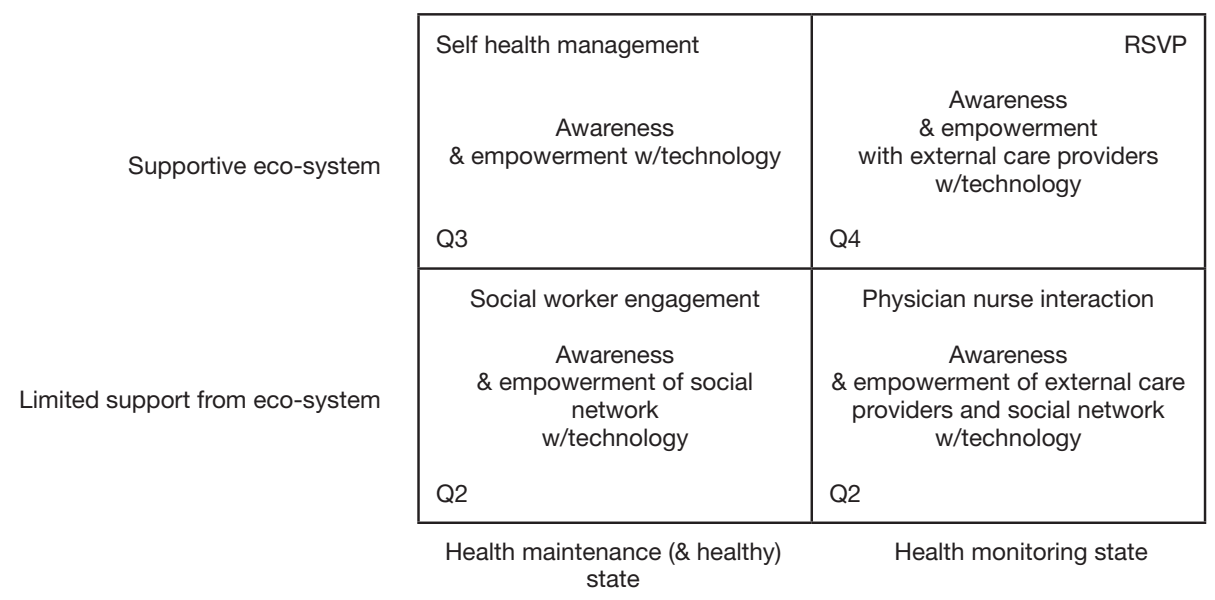

Figure 5 Strategies for engagement. 
discharge care, the role of family and social and community members in the patient engagement process is not widely discussed. They become an important player not only in supporting a patient in managing their condition outside a hospital, but also have the potential to improve a patient's self-efficacy in dealing and managing their health condition.

Patient portals are used to share information, but they are less effective when they support only one-way communication from provider to patient. For portals to become active, they need to add features such as social media forums to support discussion and two-way conversation. A two-way communication and consultation may be needed to not only engage hospitals and care providers through alerts, question/answer sessions, automatic scheduling of appointments, etc., but also to bring in other members of the patient's social network for encouragement, education, and capacity building (22). The Global to Local network case is an example of this.

Telehealth technologies are used to support communication between the patient and the provider. Their effectiveness depends on how engaged both the patient and providers are in using this communication for follow-ups and conversations (23). Again, given the varying nature of the ecosystem that supports patients, these technologies may use different types of interaction (e.g., Skype, video conferencing, text, chat, etc.) as discovered in a pilot case study in SE Michigan, as the cases in nursing home and RSPV illustrate.

Medical devices used to track health conditions (wearables) or activities (apps that track steps walked) are important in empowering patients to self-manage their health (24). However, they must be connected to other patient/physician communication tools if they are to be effective, and other technologies used by patients (iPads or TVs) at home to support effective engagement. In addition, some of these may be connected with other care providers who might provide support services, such as transportation, health, and education services. This is illustrated in the selfmanagement case in the previous section.

Infomediaries and health care sites (e.g., WebMD) are used to inform patients about the services available for them to learn about disease symptoms and criteria relevant in decision making. However, for these sites to be effective, consumers need to not only know how to seek answers to questions they have but also to stay involved in these interactions, as is shown in the case of elective cosmetic surgeries (25). Some of the members participating in these infomediaries may be peers or other patients who can answer questions or provide their experiences.

Social media can reduce patient isolation when used to share information about health and non-health care needs, combined with other uses of social media (talk to friends or play games). When social media is used via apps on iPads, it can increase the comfort level in using these apps and make them a virtual tool for conversation when patients are living alone and suffer from isolation. Call and Check's (26) work in United Kingdom shows how a postal worker can be a potential social network member to talk to seniors living at home and feeling isolated, but digital tools can enhance the patient reach to family/friends.

In summary, digital transformation strategies to engage healthcare consumers inside the hospital can be extended to patients as they leave the hospital, but these strategies need to extend the engagement to many more actors in the patient network who can help patients manage their condition within their ecosystem. In other words, the digital transformation strategy is to connect technology with various clinical and non-clinical actors (e.g., EMTs, social workers, nurse practitioners, etc.), along with patients, in order to address continuity of care. Such an extension to engage patients in their health management may or may not lead to the empowerment of patients, but it may help increase their capacity to manage their health condition. Recognizing what is needed to manage a health condition, where to go to get answers to questions that arise as well as find resources, if they have limited support, etc. are all prerequisites to being in control of the situation.

Given that much of the health care consumers' journey begins when they enter the hospital as a patient, some of this capacity building or problem solving can begin here. Hospitals can use various approaches to inform and educate patients about their health condition and engage them in care-related choices and treatment options whenever appropriate. One hospital in Michigan has started to provide patients with a book with detailed information on the care they are undergoing (8). This allows patients to record and ask questions, and to identify the actions they need to engage in once they are discharged, including making their first follow-up appointment. With the right engagement of the patient network, preferably while the patient is in the hospital and post-discharge, it is our hypothesis that patients can be empowered over time to manage their condition. In the long run, such an engagement can potentially reduce overall health care costs and improve the hospital's brand as patients make future decisions on where they go to seek support to address any health conditions. 
Table 2 Some questions related to empowerment and engagement

Empowerment assessment

- How do patients become aware of care-related symptoms and treatment options?

- What do patients look for in evaluating care-related options?

- Which organizations do patients belong to that support their knowledge gathering?

- Is there care-related support for immediate care, preventive care, and care that needs continual attention?

- Who else besides patients are engaged in decisions related to choosing care-related options?

- What resources can the patients bring to have confidence in their care-related choices?

Engagement assessment

- Who can help support patients to select care options?

- Who is paying for the care chosen?

- What trade-offs is the patient willing to make between price, time, convenient access to care, who provides it, etc.?

- How capable is the patient in self-managing their own care-emotionally and in terms of access to care facilities?

- Where is the care provided post discharge?

- What social network can the patient rely on in seeking support during care follow-up?

- Does the patient have sustained access to physicians or other care providers to support care?

\section{Conclusions}

Healthcare organizations need to tailor their digital transformation efforts to support patients in their ecosystem. Using four illustrative case studies, this paper argues that empowering patients to self-manage their health in their ecosystem begins with their engagement inside the hospital. Engagement post-discharge needs to bring together care and the non-care support network of the patient outside the hospital, and digital transformation strategies must be tailored to support patients within this network.

Future research may extend the digital transformation strategies to not only engage but also learn from such engagement various characteristics of the patient ecosystem. For example, the role a patient plays outside a hospital, the reaction they exhibit when they become aware of the disease condition, the relationship they have with community members including family and friends, and the resources they have to manage their health condition (27), all influence a patient's evolving capability to self-manage their health condition. Understanding such capacity (like business intelligence), in conjunction with the changing health condition of a patient post-discharge, can indirectly help tailor the nature of support the patient needs and the network of support hospitals can provide. For example, a patient who suddenly loses their ability to drive may need transportation support, or a patient who is divorced and has children at home needs childcare services if they are to seek care related support at external facilities.

Hospitals can't address all patient care needs postdischarge and need to leverage a mix of external resources, including digital transformation, if they are to be digitally ready to address the evolving healthcare needs of patient population. One approach under exploration is to answer select questions about patients' empowerment and engagement needs in order to assess potential gaps, if care continuity is the broader goal of healthcare organizations. Select questions shown in Table 2 provide examples.

\section{Acknowledgments}

I would like to thank Mr. David Bobrick of St Joseph Health Systems (for the RSVP system discussion), Mr. Kunal Bhatia of Rochester, MI (for the discussion of the pilot system developed to support seniors), Ms. Jacki Jones and her colleagues of Rochester, MI (for the discussion of a nursing home care post-discharge), and Ms. Fareeha Siddiqui of Seattle, WA (for the discussion of an innovation in support of indigenous and immigrant people as a part of Global to Local organization).

Funding: None. 


\section{Footnote}

Conflicts of Interest: The author has completed the ICMJE uniform disclosure form (available at http://dx.doi. org/10.21037/jhmhp.2019.09.01). The author has no conflicts of interest to declare.

Ethical Statement: The author is accountable for all aspects of the work in ensuring that questions related to the accuracy or integrity of any part of the work are appropriately investigated and resolved. The study was conducted in accordance with the Declaration of Helsinki (as revised in 2013). The study is based on four previously published case studies, referenced in the article, and acknowledged at the end of the paper. No approval by an institutional review board was needed.

Open Access Statement: This is an Open Access article distributed in accordance with the Creative Commons Attribution-NonCommercial-NoDerivs 4.0 International License (CC BY-NC-ND 4.0), which permits the noncommercial replication and distribution of the article with the strict proviso that no changes or edits are made and the original work is properly cited (including links to both the formal publication through the relevant DOI and the license). See: https://creativecommons.org/licenses/by-nc-nd/4.0/.

\section{References}

1. Desmet D, Duncan E, Scanlan J, et al. Six Building Blocks for Creating High-Performing Digital Enterprises. McKinsey \& Company, 2015. Available online: https:// www.mckinsey.com/business-functions/organization/ our-insights/six-building-blocks-for-creating-a-highperforming-digital-enterprise

2. Bossert O, Laartz J, Tor JR. Running Your Company at Two Speeds. McKinsey Quarterly, 2014. Available online: https://www.mckinsey.com/business-functions/digitalmckinsey/our-insights/running-your-company-at-twospeeds

3. Vargo SL, Lusch RF. Service-Dominant Logic" Continuing the Evolution. J Acad Mark Sci 2008;36:1-10.

4. Lusch RF, Nambisan S. Service Innovation: A ServiceDominant Logic Perspective. MIS Q 2015;39:155-75.

5. Patak L, Wilson-Stronks A, Costello J, et al. Improving patient-provider communication: a call to action. J Nurs Adm 2009;39:372-6.

6. Health Information Science and Systems. Available online: http://www.hissjournal.com/content/2/1/3

7. Weiner J, Tanniru M, Khuntia J, et al. Digital Leadership in Action in a Hospital through a Real Time Dashboard System Implementation and Experience. Available online: https://pdfs.semanticscholar.org/7a $7 \mathrm{c} / 5$ ddcfc79e11f878c8c 0809033c408f87545e.pdf

8. Fowler BL, Johns J, Tanniru MR, et al. Engaging patients through Multi-Disciplinary Rounding - The case study at a Michigan hospital. Available online: http://www.sciedu. ca/journal/index.php/jha/article/view/13390

9. Caritas Project. Available online: http:// www.thecaritasproject.info/aplacetoflourish/ awardWinner_2014.html

10. Kripalani S, Theobald CN, Anctil B, Vasilevskis EE. Reducing hospital readmission rates: current strategies and future directions. Annu Rev Med 2014;65:471-85.

11. Johnston L, Zemanek J, Reeve MJ, et al. The evidence for using mHealth technologies for diabetes management in low- and middle-income countries. J Hosp Manag Health Policy 2018; 2:35

12. Olguin DO, Gloor PA, Pentland A. Wearable Sensors for Pervasive Healthcare Management. Available online: http://www.ickn.org/documents/PervCompHealth_ DDO2009.pdf

13. Hswen Y, Bickham DS. Engaging African American teens in co-creating and disseminating social media based HIV prevention messages. J Hosp Manag Health Policy 2018;2:41.

14. Vargo SL, Akaka MA, Wieland H. Innovation through institutionalization: A service ecosystems perspective. Ind Marketing Mgmt 2015;44:63-72.

15. Simon HA. Administrative behaviour. New York, NY: Macmillan, 1947.

16. Porter ME. Competitive Advantage: Creating and Sustaining Superior Performance. New York: Simon and Schuster, 1985.

17. RSVP. Available online: http://www.stjoeshealth.org/body. cfm?id=7598\&action=detail\&ref=5532, 2016

18. Benjenk I, Chen J. Effective mental health interventions to reduce hospital readmission rates: a systematic review. J Hosp Manag Health Policy 2018. doi: 10.21037/ jhmhp.2018.08.05

19. Jones J, Klaver J, Kazziha S. Lessons Learned From Implementing a Readmissions Reduction Program. Available online: https://blog.acc.org/post/lessons-learnedfrom-implementing-a-readmissions-reduction-program/

20. Global To Local. Available online: https://www. wghalliance.org/initiative/global-to-local/ 
21. Bhatia K. Care'Tainment: Research \& Development Prototype, 2017; 2nd Graduate Research Conference, Oakland Univ. Available online: https://www.oakland. edu/Assets/Oakland/grad/files-and-documents/GraduateStudent-Research-Conference/2017

22. Jarzabek S, Cheong K, Lim YW, et al. CBT Assistant Platform: web/mobile co-design solution for cognitive behavioural therapy. J Hosp Manag Health Policy 2018;2:34.

23. Sendler DJ. Combining standard psychiatric care with e-health follow up solutions - a viewpoint on making psychiatric care cost-effective for millions of patients and professionally satisfactory for providers. J Hosp Manag

doi: 10.21037/jhmhp.2019.09.01

Cite this article as: Tanniru M. Engagement leading to empowerment-digital innovation strategies for patient care continuity. J Hosp Manag Health Policy 2019;3:28.
Health Policy 2018;2:40.

24. Chiauzzi E, Rodarte C, DasMahapatra P. Patient-centered activity monitoring in the self-management of chronic health conditions. BMC Med 2015;13:77.

25. Khuntia J, Yim D, Tanniru MR, et al. Patient Empowerment and Engagement with a Health Infomediary. Health Policy Technol 2017;6:40-50.

26. UK posties to "call and check" on vulnerable and isolated Brits. Available online: https://www.callandcheck.com/ news/uk-posties-to-call-and-check-on-vulnerable-andisolated-brits/

27. Doremus BL. The four Rs: social diagnosis in health care. Health Soc Work 1976;1:120-39. 